\section{Consumer Preferences for Low-input Turfgrasses: A Conjoint Analysis}

Kari Hugie ${ }^{1}$

Department of Horticulture, University of Minnesota, 1970 Folwell Avenue, St. Paul, MN 55108

\author{
Chengyan Yue ${ }^{2,4}$ \\ Departments of Applied Economics and Horticultural Science, University of \\ Minnesota, 1970 Folwell Avenue, St. Paul, MN 55108
}

\author{
Eric Watkins ${ }^{3}$ \\ Department of Horticulture, University of Minnesota, 1970 Folwell Avenue, \\ St. Paul, MN 55108
}

Additional index words. home lawn, market segmentation, northern Midwest, relative importance, sustainable

\begin{abstract}
Traditional turfgrasses found in residential lawns provide a functional and aesthetically pleasing landscape if provided adequate resource inputs, yet, as available natural resources become more limited and public concerns grow stronger about the ecological effects of urban turfgrass management, it becomes increasingly important to pursue alternative landscape options. There are non-traditional turfgrasses that require fewer resource inputs that could be made available to homeowners. The objective of this study was to estimate consumer preferences and the relative importance of aesthetic and maintenance attributes of turfgrasses as well as identify potential market segments of the residential turfgrass market. Conjoint analysis was conducted on survey responses of 116 Minnesota homeowners. The results indicated that maintenance attributes of turfgrasses, specifically irrigation requirement, significantly affected consumer purchasing behavior. The analysis also identified four potential market segments, the Price Conscious segment, the Shade Adaptation segment, the Mowing Conscious segment, and the Water Conscious segment.
\end{abstract}

Lawns are an important part of American culture and are nearly universal throughout the urban landscape. As a result, turfgrass covers more acreage in the United States than any other irrigated crop (Milesi et al., 2005). Over half of U.S. households participate in lawn care practices and spend an average of \$213 annually on lawn care services and products (Butterfield, 2003). Haydu et al. (2006) estimated the total value added to the U.S. economy from the lawn care industry in 2002 was $\approx \$ 13.3$ billion.

If managed properly, turfgrass benefits both society and the environment. Turfgrass can reduce soil erosion and surface runoff (Krenitsky et al., 1998), mitigate urban heat island effects (Peters et al., 2011), sequester carbon (Qian et al., 2010) as well as provide recreational and aesthetic benefits to society (Beard and Green, 1994). However, turfgrass

Received for publication 27 Mar. 2012. Accepted for publication 31 May 2012.

This material is based on research supported by the Cooperative State Research, Education, and Extension Service, U.S. Department of Agriculture, under Agreement No. 2009-34381-20044.

${ }^{1}$ Graduate Assistant.

${ }^{2}$ Bachman Endowed Chair in Horticultural Marketing and Assistant Professor.

${ }^{3}$ Associate Professor.

${ }^{4}$ To whom reprint requests should be addressed; e-mail yuechy@umn.edu. fewer resource inputs or low-input turfgrass species. For example, kentucky bluegrass (Poa pratensis L.) and perennial ryegrass (Lolium perenne L.) are the most widespread grass species found in residential landscapes in the northern Midwest, but they require considerable amounts of resource inputs to maintain a lawn of satisfactory quality (Turgeon, 2005). Several non-traditional grass species that provide acceptable, even superior, quality when maintained with fewer resource inputs have been identified in studies conducted throughout the northern Midwest. Diesburg et al. (1997) established field trials in seven states throughout the northern Midwest to evaluate alternative grass species under minimal fertility and no irrigation over a 3-year period. Although they observed some variation in species performance between sites, in general, tall fescue (Festuca arundinacea Schreb.), sheep fescue (Festuca ovina L.), and colonial bentgrass (Agrostis capillaris L.) performed well across the region. In a similar 2-year low-input, alternative grass species field trial conducted in the northern Midwest, hard fescue [Festuca trachyphylla (Hack.) Krujina], tall fescue, sheep fescue, and colonial bentgrass provided an acceptable turfgrass stand throughout the region under the low-maintenance regime (Watkins et al., 2011). Additionally, several native grass species, including tufted hairgrass [Deschampsia caespitosa (L.) P. Beauv.] and prairie junegrass [Koeleria macrantha (Ledeb.) Shult.], have also shown potential in regional trials for use as low-input turfgrasses (Mintenko et al., 2002; Watkins et al., 2011).

There have been multiple studies conducted to investigate residential landscape preferences, but most have focused on homeowner preferences for xeriscapes (Larsen and Harlan, 2006; Spinti et al., 2004; Yabiku et al., 2008). Results from these studies are currently most relevant in arid regions where the strain on freshwater resources is greater than in the humid northern Midwest. Homeowners generally value traditional, wellgroomed residential landscapes (Zheng et al., 2011), and an aesthetically pleasing landscape can even enhance the perceived value of homes (Behe et al., 2005). Studies also suggest consumers are becoming increasingly environmentally conscious and making more ecologically minded purchasing decisions (Yue et al., 2011). Helfand et al. (2006) found that consumers in the northern Midwest were likely to adopt more environmentally beneficial landscape designs. Previous research suggests that a potential market may exist for low-input turfgrasses in residential landscapes (Helfand et al., 2006; Wolfe and Zajicek, 1998), but there have been no formal studies investigating consumer preferences for turfgrass attributes. For the use of non-traditional, low-input turfgrasses to be a successful strategy to reduce resource inputs in the urban landscape, the consumer market for low-input turfgrasses as well as consumer preferences for aesthetic and maintenance attributes of turfgrasses must first be 
investigated and characterized. Therefore, the objectives of this study were to 1) characterize the relative importance of both aesthetic and maintenance attributes of turfgrasses with residential homeowners; and 2) identify and characterize potential market segments within the residential turfgrass market. This information is not only useful for marketing and sales professionals to identify the target consumer market, but it also provides valuable information and direction for turfgrass breeders and seed producers.

\section{Materials and Methods}

Consumer satisfaction for a product as a whole is determined by the value placed on each of the various attributes that comprise the product (Baker, 1999), and conjoint analysis allows researchers to estimate how much individual attributes and attribute levels contribute to overall consumer satisfaction. Conjoint analysis is widely used for marketing research (Green et al., 2001) and has been used to examine consumer preferences for many horticultural products (Behe, 2006; Behe et al., 1999, 2005; Campbell et al., 2004; Frank et al., 2001; Hall et al., 2010). In this study, conjoint analysis was used to characterize consumer preferences for turfgrass attributes as well as determine their relative importance.

Attributes. Focus groups were conducted in Apr. 2010 to help determine the set of turfgrass attributes to include in the conjoint analysis. Key attributes of most concern to consumers were price, shade adaptation, aesthetic characteristics (e.g., color), and maintenance characteristics (e.g., mowing requirement). Based on the results from the focus group discussions, the following nine attributes were included in the conjoint analysis: price, shade adaptation, color, texture, amount of weed infestation, irrigation requirement, fertility requirement, mowing requirement, and origin. Other potential attributes such as pest resistance and wear tolerance were determined to have less importance to homeowners and were excluded.

The difference in the price of turfgrass seed is highly dependent on species. Four representative price points were chosen for the study (\$5.00, $\$ 10.00, \$ 15.00$, and $\$ 20.00$ ), and to ensure ease of interpretation, price was expressed as the cost to seed $1000 \mathrm{ft}^{2}$. The appropriate price range was determined by observing the market price of turfgrass seed and consulting with turfgrass seed professionals throughout the Minneapolis-St. Paul metropolitan area. Aesthetic attributes of turfgrass also influence consumer preference. Traditionally, consumers value dark, finer textured turfgrass stands with no weed infestation. Two levels of color ("dark" and "light"), texture ("coarse" and "fine"), and weed infestation ("yes" or "no") were chosen for the conjoint design. Maintenance requirements are also likely to influence consumer preference not only as a result of interest in cost savings, but also attributable to increasing interest in environmental stewardship. Three levels of irrigation, fertility, and mowing requirements were chosen for the conjoint design. Irrigation requirement was expressed as frequency of irrigation required during June, July, and August ("low: less than once a week," "moderate: one to two times per week," and "high: three to five times per week"), and mowing requirement was also expressed as a frequency ("once a month," "every other week," and "one to two times per week"). Fertility requirement was expressed as pounds of nitrogen required annually ("1 lb N/1000 ft²/year," "2 lbs N/ $1000 \mathrm{ft}^{2} /$ year," and "3 lbs N/1000 ft $2 /$ year"). Many home lawns have shaded areas, and consumers have shown an interest in native plants for landscapes (Helfand et al., 2006). Thus, two levels of shade adaptation ("sun only" and "sun and shade") and origin ("U.S. native" and "non-native") were also included in the conjoint design.

Survey. The total number of possible attribute combinations was 3456 . Therefore, it was impractical to have respondents evaluate all combinations, so a fractional-factorial design was used. The fractional-factorial design was generated using JMP® 8 software (SAS Institute Inc., Cary, NC), and non-realistic profiles were eliminated from the design (Green and Srinivasan, 1978). The final set of profiles consisted of 32 combinations, which maximized orthogonality and level balance (levels of an attribute occurred with equal frequency).

Turfgrass plots were used as the stimuli to estimate the relative importance of aesthetic attributes as well as the other turfgrass attributes. Plots were used as stimuli because estimations from both verbal questions and photographs may not accurately represent true preferences (Zheng et al., 2011), and the use of real products may allow for more accurate estimation of consumer preference (Alfnes et al., 2006; Yue and Tong, 2009). Turfgrass plots were $1.0 \mathrm{~m} \times 1.5 \mathrm{~m}$ and consisted of monostands of kentucky bluegrass, perennial ryegrass, hard fescue, colonial bentgrass, tufted hairgrass, and prairie junegrass. There were 648 turfgrass plots at the study site, which varied in color, texture, and natural weed presence from which the 32 turfgrass plots (i.e., stimuli) were chosen. Turfgrass plots were chosen so that differences in color and texture could be clearly differentiated. Plots that were categorized as absent of weeds had no weeds, and plots that were categorized as having weeds had $\approx 10 \%$ to $20 \%$ natural weed encroachment. The 32 turfgrass plots included in the study were clearly labeled and delineated. Signs were placed in front of each turfgrass plot and were labeled with one level of price, shade adaptation, origin, and specific maintenance requirements. Color, texture, and weed presence were not labeled on the signs so consumer valuation of aesthetic attributes was based solely on participants' observations. Because price was expressed as the cost per area, an area adjacent to the turfgrass plots equivalent to $1000 \mathrm{ft}^{2}$ was marked off for participants to use as a reference.
Participants were recruited by placing advertisements in 13 local newspapers throughout the Minneapolis-St. Paul metropolitan area as well as advertisements on $<\mathrm{http}$ :// www.minneapolis.craigslist.org $>$. Participants came to the study site located at the University of Minnesota Turfgrass Research, Outreach, and Education Center located in St. Paul, MN, and were compensated $\$ 30.00$ each for completing the on-site survey. To ensure the results were representative of the consumer market, only subjects with a home lawn and the ability to make lawn care decisions were allowed to participate in the study. The survey was conducted on 12 June 2010. To reduce the number of participants taking the survey at one time, there were five separate sessions throughout the day, and there were 20 to 30 participants in each session. Participants were asked to rate each turfgrass plot on a 5-point Likert scale $(1=$ extremely dislike, $5=$ extremely like). They were also asked to fill out a short questionnaire about demographic and lawn carespecific information, including age, gender, level of education, income, household size, and current lawn care practices. In the questionnaire participants were also asked questions about their attitudes and preferences about home lawn maintenance practices. The study protocol was approved by the University of Minnesota Institutional Review Board before implementation.

Data analysis. Preference ratings were analyzed using CONJOINT in SPSS 19.0 (SPSS, Inc., Chicago, IL). For the conjoint model, a part-worth functional form was selected for each attribute except for price, which was represented with an ideal point (quadratic) model. Vector (linear) and ideal point models for price were evaluated using the method described by Green and Srinivasan (1990), and the ideal point model was determined to have the smallest prediction error. Ordinary least squares regression was used to estimate each participant's part-worth and ideal coefficients (i.e., utilities) for each attribute level. Each variable, except for price, was effects coded so the utilities of each level within an attribute summed to zero. Individual regression models were fit to each participant instead of using an aggregate model, which not only reduces potential bias resulting from differences in preferences among individuals, but also allows participants to be grouped into consumer segments by clustering individuals with similar coefficients (Green and Helsen, 1989). The relative importance of each attribute was also calculated for each individual using the following formula:

$$
R I_{i}=\left(\frac{R G_{i}}{\sum_{i=1}^{9} R G_{i}}\right) \times 100
$$

where $\mathrm{RI}_{i}$ is the relative importance of the $i$ th attribute and $R G$ is the range of the utility coefficients for attribute $i$. Relative importance represents the magnitude of importance an attribute contributes to a consumer's valuation and purchasing decision. 
Cluster analysis was performed in SPSS 19.0 (SPSS, Inc.) using the estimated coefficients for each participant. Multiple clustering algorithms were used to determine the ideal number of clusters, namely Ward's Minimum Variance and Complete Linkage (Campbell et al., 2004; Frank et al., 2001; Hall et al., 2010). A four-cluster solution was selected based on distinctness and interpretability (Kotler and Armstrong, 1994). Mean utility values as well as the mean response to questions about attitudes toward lawn care practices for each of the four segments were tested against the overall sample mean using two-tailed $t$ tests. Additionally, multiple pairwise comparisons between segments were also conducted on utility and relative importance estimates as well as demographic and behavioral variables using Dunnett's C test in SPSS 19.0 (SPSS, Inc.).

\section{Results and Discussion}

Overall sample. One hundred thirty-six participants completed the survey. However, only 116 participants were used in the conjoint and cluster analyses as a result of missing values. Participants' age ranged from 19 to 77 years old and the average age of the sample was 44.7 years old. Approximately half of the sample was female (50.9\%). Eleven percent of participants earned $\$ 25,000$ or less annually, $35.3 \%$ of participants earned between $\$ 25,001$ and $\$ 50,000,28.4 \%$ earned between $\$ 50,001$ and $\$ 80,000$, and $25.0 \%$ earned more than $\$ 80,000$. Forty-nine percent of participants worked full-time, $15.5 \%$ worked part-time, $5.2 \%$ were students, $13.8 \%$ were retired, and $9.5 \%$ were unemployed (6.9\% of responses were missing values). Fourteen percent of participants had earned a high school diploma or less, $62.1 \%$ had completed some college or earned a college diploma, and $23.3 \%$ had completed some graduate school or earned a graduate degree. Only $16.4 \%$ of participants hired an external lawn care service, and $81.0 \%$ of participants had purchased turfgrass seed in the past 10 years. Approximately $22 \%$ of participants spent less than $\$ 100$ on lawn care annually, $43.1 \%$ spent between $\$ 100$ and $\$ 300$, and $24.1 \%$ of participants spent more than $\$ 300$ on annual maintenance ( $11.2 \%$ of responses were missing values).

The mean utility for each attribute level, SE, relative importance, and $R^{2}$ for the overall sample and each consumer segment are reported in Table 1 as well as mean comparisons between each segment and the overall sample and multiple pairwise comparisons between consumer segments. Higher utility values indicate a greater preference, and relative importance represents the extent to which an attribute contributes to consumers' overall valuation of the product. The conjoint model accounted for $77 \%$ of the variation in participant response. Overall, participants placed the highest relative importance on irrigation requirement $(15.98 \%)$ and price $(15.45 \%)$ followed by mowing requirement $(13.74 \%)$ and fertility requirement $(12.06 \%)$.
Less relative importance was placed on shade adaptation, aesthetic attributes, and origin. Native grasses are typically more expensive than non-native grasses (Smith and Whalley, 2002). As a result of the elimination nonrealistic profiles (e.g., U.S. native and \$5.00), there may have been an interaction effect between price and origin.

Participants preferred dark, fine textured turfgrasses with no weed infestation, low (less than once a week) and moderate (one to two times per week) irrigation requirements as well as the low (once a month) mowing requirement. Preferences for shade adaptation, texture, color, fertility, and origin varied widely, as indicated by the large SES for the utilities. Although the statistics of the entire sample provide useful insight, groups of participants whose preferences differ from the overall sample can lead to biased results (Green and Krieger, 1991). Four consumer segments, the Price Conscious, Shade Adaptation, Mowing Conscious, and Water Conscious segments, were identified through cluster analysis by grouping participants with similar preferences. Each segment had characteristically different importance values as well as preferences in comparison with each other and the overall sample. Mean comparisons between segments and the overall sample and multiple pairwise comparisons between consumer segments regarding demographics and attitudes are presented in Table 2. Although there were significant $(\alpha=0.05)$ differences in attitudes among the four segments, there were no significant differences in demographics between consumer segments.

Segment I. Participants in the first segment, the "Price Conscious" participants, comprised $20.69 \%$ of the sample. Participants in this group placed significantly higher relative importance on price $(18.97 \%)$ compared with the Water Conscious segment and the overall sample as well as on turfgrass plots with no weed infestation (13.84\%) relative to the other three consumer segments. The Price Conscious segment strongly preferred the low irrigation requirement and was the only group that disliked the moderate irrigation requirement. These participants also highly favored the moderate fertility requirement and had a strong preference for non-native grasses, which could be a result of the potential interaction effect between origin and price.

In comparison with the overall sample, participants in the Price Conscious segment spent significantly less on lawn maintenance and also indicated they would be less willing to sacrifice the aesthetic appeal of their lawn to reduce maintenance inputs. Turfgrasses most likely to appeal to these participants are low-cost grasses with an aggressive growth habit making them likely to out-compete weeds. Most participants in this segment, like the overall sample, slightly to strongly agreed (rating 5 or greater) that pesticides were harmful to human health $(87.5 \%)$ and the environment (91.7\%), so naturally weedsuppressive, allelopathic turfgrasses may also strongly appeal to these consumers (Bertin et al., 2009).
Segment II. Participants in the second segment, the "Shade Adaptation" segment, represented $31.03 \%$ of the sample. They placed significantly higher relative importance on shade adaptation relative to the overall sample and the Water Conscious segment, and they had a significantly stronger preference for turfgrasses adapted to both sun and shade compared with the other three consumer segments. This group also placed significantly more importance on texture than the overall sample, but their preferences for fine- and coarse-textured turfgrasses were not significantly different from the other segments. The Shade Adaptation segment placed significantly lower relative importance on irrigation requirement compared with the overall sample and the Water Conscious segment, and the presence of weeds was the least important turfgrass attribute to these participants. Turfgrass advertised as a "sun and shade mix" would more likely appeal to these participants compared with turfgrass advertised for aesthetic or low-maintenance attributes.

Segment III. Participants in Segment III, the "Mowing Conscious" participants, comprised $28.45 \%$. These participants placed the greatest importance on mowing requirement and placed significantly less relative importance on the presence of weeds compared with the overall sample. They were also the only consumer segment that favored the low fertility requirement. Unlike the other three segments, the average coefficients for price were positive as was the utility for native origin. Considering the potential interaction effect between price and origin, this may indicate that participants in the Mowing Conscious segment were not as sensitive to price and preferred native grasses. This group also had the highest percentage of women. This segment may indicate a potential market for more expensive, native turfgrasses that are slow-growing and low maintenance.

Segment $I V$. The fourth segment, the "Water Conscious" participants, comprised $19.83 \%$ of the sample and placed an extremely high relative importance on irrigation requirement $(30.12 \%)$. Mowing requirement was the second most important attribute. Participants in this segment placed a significantly lower relative importance on price and texture relative to the overall sample, but they strongly preferred darker grasses.

The Water Conscious segment had the highest percentage of men and a significantly higher level of education than the overall sample. The defining characteristic of participants in this segment was their strong concern for water conservation. Compared with the overall sample, the Price Conscious segment, and the Shade Adaptation segment, these participants indicated they would be more likely to purchase low-input turfgrasses. Low-maintenance, drought-tolerant turfgrasses, which remain green throughout the dry periods of the growing season, would likely strongly appeal to this group of participants. 
Table 1. Relative importance and utility for nine turfgrass attributes in a conjoint study of consumer preference for low-input turfgrasses among 116 homeowners in Minneapolis-St. Paul, MN.

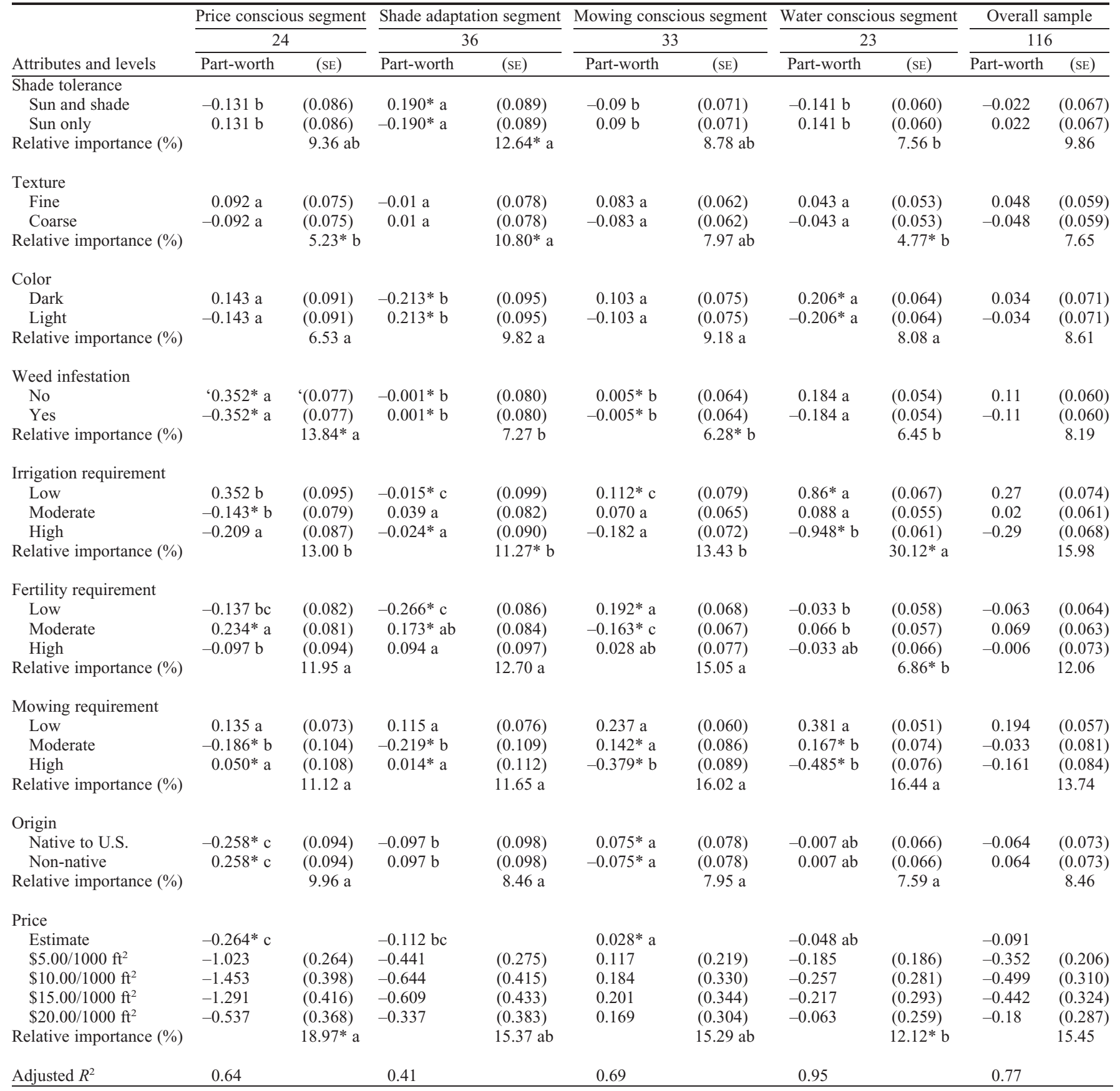

*Significant at the 0.05 level when compared with the overall sample in a two-tailed $t$ test. Segment means within the same row with the same letter are not significantly different $(\alpha=0.05)$ according to Dunnett's C test.

\section{Conclusions}

The ecological impact of urban and suburban lawn care practices has become a major concern in recent decades. The use of nontraditional, low-input turfgrasses for home lawns may help reduce resource inputs and environmental impacts associated with residential lawn care. This study characterizes consumer preferences for nine attributes of turfgrass and identifies four distinct potential market segments. Although preferences differed between segments, in general participants placed more importance on maintenance attributes than on aesthetic attributes.
These results suggest that information about the maintenance requirements of turfgrass significantly influence consumer purchasing decisions and that non-traditional, low-input turfgrasses would likely be accepted in the residential turfgrass market.

Overall, irrigation requirement was the most important turfgrass attribute, and only slight importance was placed on shade adaptation, color, texture, presence of weeds, and origin. However, clear differences in preference and relative importance among these attributes became apparent after participants were clustered into segments. The Price Conscious and Shade Adaptation segments were more sensitive to price and placed less overall importance on maintenance attributes than participants in the Mowing Conscious and Water Conscious segments. Still, it is evident that reduced irrigation requirement is the most valued low-maintenance attribute of turfgrasses by homeowners in the Minneapolis-St. Paul metropolitan area. Participants' responses to statements about water use indicated that the cost of water was not a major motivation behind the strong preference for turfgrasses with a low irrigation requirement, but instead that environmental concern was a more likely motivation. These results strongly suggest that the introduction 
Table 2. Demographic characteristics and mean responses to statements about attitudes and perceptions of turfgrass of each consumer segment.

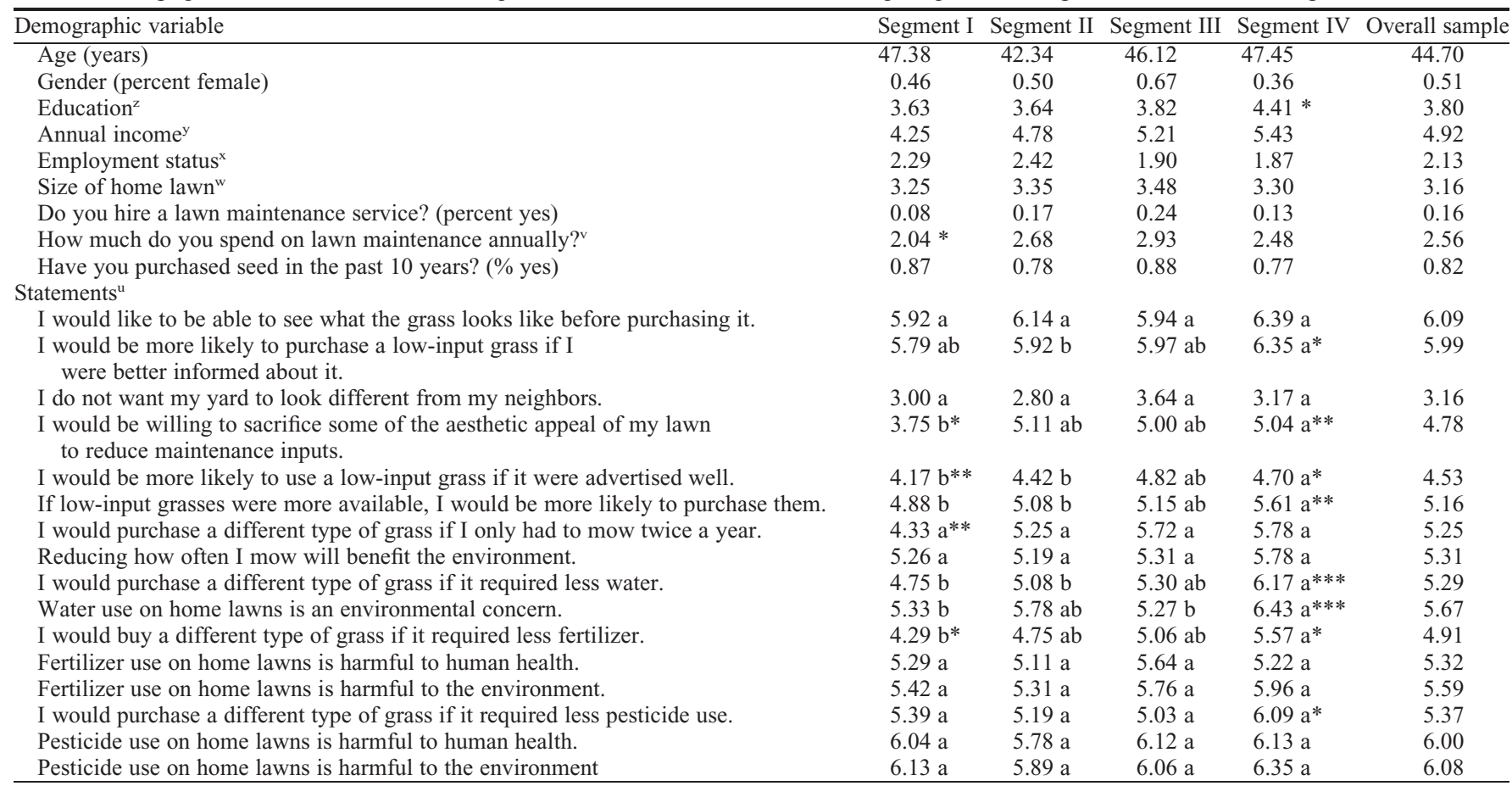

${ }^{{ }^{2} E d u c a t i o n ~ w a s ~ r e p o r t e d ~ o n ~ a ~} 1$ to 6 scale: 1 = some high school or less; 2 = high school diploma; 3 = some college; $4=$ college diploma; $5=$ some graduate school; $6=$ graduate degree.

'Income was reported on a 1 to 8 scale: $1=\$ 15,000$ or under; $2=\$ 15,001-\$ 25,000 ; 3=\$ 25,001-\$ 35,000 ; 4=\$ 35,001-\$ 50,000 ; 5=\$ 50,001-\$ 65,000 ; 6=\$ 65,001-$ $\$ 80,000 ; 7=\$ 80,001-\$ 100,000 ; 8=$ over $\$ 100,000$.

${ }^{x}$ Employment was reported on a 1 to $5: 1$ = full-time; 2 = part-time; $3=$ student; 4 = retired; 5 = unemployed.

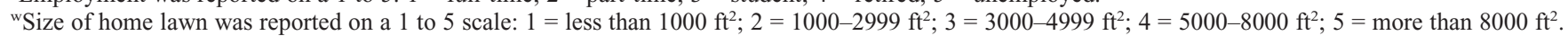

${ }^{\mathrm{v}}$ Annual expenditure was reported on a 1 to 5 scale: $1=$ less than $\$ 100.00 ; 2=\$ 100.00-\$ 199.00 ; 3=\$ 200.00-\$ 299.00 ; 4=\$ 300.00-\$ 400.00 ; 5=$ more than $\$ 400.00$.

"Participants were asked to indicate on a scale of 1 to 7 , which best described their attitude toward the statements $(1=$ strongly disagree and $7=$ strongly agree).

Single asterisk $(*)$, double asterisks $(* *)$, and triple asterisks $(* * *)$ denote significance at $0.10,0.05$, and 0.01 levels, respectively, when compared with the overall sample in a two-tailed $t$ test. Means within the same row with the same letter are not significantly different $(\alpha=0.05)$ according to Dunnett's $\mathrm{C}$ test.

of low-input turfgrasses to the market might be a viable strategy to reduce water use in the urban landscape.

Preferences for mowing and fertility requirements were not as consistent as the preference for irrigation requirement. Of the three maintenance attributes, the second most importance was placed on mowing requirement. Approximately $70 \%$ of participants agreed with the statement "reducing how often I mow will benefit the environment," suggesting participants' motivations behind placing high importance on reduced mowing were not only based on cost and time savings, but also potentially on environmental concerns about fossil fuel use.

More than $75 \%$ of participants agreed that fertilizers were harmful to the environment, which is similar to the findings of Meyer et al. (2001), yet all participants, except for those in the Mowing Conscious segment, preferred the moderate fertility requirement. The University of Minnesota Extension program recommends $2 \mathrm{lbs} \mathrm{N} / 1000 \mathrm{ft}^{2}$ per year for moderately maintained home lawns in (Mugaas, 1995). Considering recommendations and restrictions on phosphorus-containing lawn fertilizers currently in effect in Minnesota, it is probable that most homeowners believe that a moderate amount of fertility is not detrimental to the environment.
Previous research suggests that consumers prefer native plants in residential landscapes (Helfand et al., 2006; Zadegan et al., 2008). These results suggest the same preference may not exist for turfgrasses, although inference on consumer preference for turfgrass origin is limited as a result of the potential interaction between origin and price. Only participants in the Mowing Conscious segment preferred native turfgrasses, yet they still placed little relative importance on origin compared with other attributes. These results do support that there is consumer demand for turfgrasses adapted to shade, which are already available on the market. Among the aesthetic attributes, participants had the strongest preference for turfgrass plots without weeds. Given that herbicides are the most commonly used pesticides on home lawns (Meyer et al., $2001)$ and a majority of participants (68.9\%) indicated they would likely purchase a different type of grass if it required fewer pesticide applications, the development and introduction of allelopathic turfgrasses for the residential market may warrant further investigation.

Participants in the Water Conscious segment had the highest level of education, which has previously been reported as a significant sociodemographic predictor for en- vironmentally conscious consumer behavior (Samdahl and Robertson, 1989), although more recent studies have failed to find connections between environmentally conscious purchasing behavior and consumer demographics, which is likely the result of more widespread knowledge about environmental issues (Roberts, 1996). This may help explain the lack of significant differences in demographics between consumer segments in this study. Roberts (1996) suggested that demographics and an individual's concern for the environment were much less accurate at predicting consumer behavior in comparison with perceived consumer effectiveness, which is a measure of consumers' belief in the ability of the actions of an individual to significantly affect environmental problems. Considering that the majority of Minnesota homeowners believe their lawn care practices can have a significant effect on the environment, there is a relatively high level of perceived consumer effectiveness in regard to environmental issues surrounding residential lawn care (Meyer et al., 2001). This additionally supports the likelihood of consumers adopting non-traditional, low-input turfgrasses.

The vast majority of participants (95.7\%) indicated that they would be more likely to purchase low-input turfgrasses if provided 
more information. Efforts to increase public knowledge about sustainable lawn care practices and awareness of low-input turfgrasses may also be an effective, long-term strategy to reduce resource inputs used in residential landscapes (Carpenter and Meyer, 1999; Hurd, 2006). Although the results presented in this study highlight the importance of maintenance attributes of turfgrass to consumers, the results should also be interpreted with caution. It is also worth noting that there are different ways to segment participants and that the number of clusters chosen is, to some extent, subjective. We could have further segmented participants into subsegments, likely identifying areas of differing preference within each of the four segments. The sample size for the conjoint analysis $(\mathrm{n}=116)$ was relatively small compared with other conjoint studies, and the results may not be representative of other states and regions of the United States. Despite these limitations, the results do imply that the introduction of low-input turfgrasses to the residential consumer market warrants further consideration.

\section{Literature Cited}

Abraham, E.M., B. Huang, S.A. Bonos, and W.A. Meyer. 2004. Evaluation of drought resistance for Texas bluegrass, kentucky bluegrass, and their hybrids. Crop Sci. 44:1746-1753.

Alfnes, F., A.G. Guttormsen, G. Steine, and K. Kolstad. 2006. Consumers' willingness to pay for the color of salmon: A choice experiment with real economic incentives. Amer. J. Agr. Econ. 88:1050-1061.

Baker, G.A. 1999. Consumer preferences for food safety attributes in fresh apples: Market segments, consumer characteristics, and marketing opportunities. J. Agr. Resour. Econ. 24:80-97.

Beard, J.B. and R.L. Green. 1994. The role of turfgrasses in environmental protection and their benefits to humans. J. Environ. Qual. 23:452-460.

Behe, B.K. 2006. Conjoint analysis reveals consumers prefer long, thin asparagus spears. HortScience 41:1259-1262.

Behe, B.K., J. Hardy, S. Barton, J. Brooker, T. Fernandez, C. Hall, and J. Hicks. 2005. Landscape plant material, size, and design sophistication increase perceived home value. J. Environ. Hort. 23:127-133.

Behe, B.K., R. Nelson, S. Barton, C. Hall, C.D. Safley, and S. Turner. 1999. Consumer preferences for geranium flower color, leaf variegation, and price. HortScience 34:740-742.

Bertin, C., A.F. Senesac, F.S. Rossi, A. DiTommaso, and L.A. Weston. 2009. Evaluation of selected fine-leaf fescue cultivars for their turfgrass quality and weed suppressive ability in field settings. HortTechnology 19:660-668.

Bonos, S.A., B.B. Clarke, and W.A. Meyer. 2006. Breeding for disease resistance in the major coolseason turfgrasses. Phytopathology 44:213-236.

Butterfield, B. 2003. National gardening survey 2002. Natl. Gardening Assn., Burlington, VT.

Campbell, B.L., R.G. Nelson, R.C. Ebel, W.A. Dozier, J.L. Adrian, and B.R. Hockema. 2004. Fruit quality characteristics that affect consumer preferences for satsuma mandarins. HortScience 39:1664-1669.

Carpenter, P.J. and M.H. Meyer. 1999. Edina Goes Green Part III: A survey of consumer lawn care knowledge and practices. HortTechnology 9:491-494.
Castle, S. and S.E. Naranjo. 2009. Sampling plans, selective insecticides and sustainability: The case for IPM as 'informed pest management.' Pest Mgt. Sci. 65:1321-1328.

DaCosta, M. and B. Huang. 2006. Deficit irrigation effects on water use characteristics of bentgrass species. Crop Sci. 46:1779-1786.

Devitt, D.A., K. Carstensen, and R.L. Morris 2008. Residential water savings associated with satellite-based ET irrigation controllers. J. Irrig. Drain. E-ASCE. 134:74-82.

Diesburg, K.L., N.E. Christians, R. Moore, B. Branham, K. Danneberger, Z.J. Reicher, T. Voigt, D.D. Minner, and R. Newman. 1997. Species for low-input sustainable turf in the U.S. Upper Midwest. Agron. J. 89:690-694.

Frank, C.A., R.G. Nelson, E.H. Simonne, B.K. Behe, and A.H. Simonne. 2001. Consumer preferences for color, price, and vitamin C content of bell peppers. HortScience 36:795-800.

Green, P.E. and K. Helsen. 1989. Cross-validation assessment of alternatives to individual-level conjoint analysis: A case study. J. Mark. Res. 26:346-350.

Green, P.E. and A.M. Krieger. 1991. Segmenting markets with conjoint analysis. J. Mark. 55:2031

Green, P.E., A.M. Krieger, and Y. Wind. 2001. Thirty years of conjoint analysis: Reflections and prospects. Interfaces 31:S56-S73.

Green, P.E. and V. Srinivasan. 1978. Conjoint analysis in consumer research: Issues and outlook. J. Consum. Res. 5:103-123.

Green, P.E. and V. Srinivasan. 1990. Conjoint analysis in marketing: New developments with implications for research and practice. J. Mark. 54:3-19.

Hall, C.R., B.L. Campbell, B.K. Behe, C. Yue, R.G. Lopez, and J.H. Dennis. 2010. The appeal of biodegradable packaging to floral consumers. HortScience 45:583-591.

Haydu, J.J., A.W. Hodges, and C.R. Hall. 2006. Economic impacts of the turfgrass and lawncare industry in the United States. Fla. Coop. Ext. Serv., IFAS, Univ. of Fla., Gainesville, FL. $<$ http://edis.ifas.ufl.edu $>$.

Helfand, G.E., J.S. Park, J.I. Nassauer, and S. Kosek. 2006. The economics of native plants in residential landscape designs. Landsc. Urban Plan. 78:229-240.

Hurd, B.H. 2006. Water conservation and residential landscapes: Household preferences, household choices. J. Agr. Resour. Econ. 31:173-192.

Karcher, D.E., M.D. Richardson, K. Hignight, and D. Rush. 2008. Drought tolerance of tall fescue populations selected for high root/shoot ratios and summer survival. Crop Sci. 48:771-777.

Kotler, P. and G. Armstrong. 1994. Principles of marketing. $6^{\text {th }}$ Ed. Prentice-Hall, Englewood Cliffs, NJ.

Krenitsky, E.C., M.J. Carroll, R.L. Hill, and J.M. Krouse. 1998. Runoff and sediment losses from natural and man-made erosion control materials. Crop Sci. 38:1042-1046.

Larsen, L. and S.L. Harlan. 2006. Desert dreamscapes: Residential landscape preference and behavior. Landsc. Urban Plan. 78:85-100.

Massachusetts Department of Environmental Protection (MassDEP). 2010. Municipal water use restrictions. Massachusetts Office of Energy and Environmental Affairs: Boston, MA. <http:// www.mass.gov/dep/water/resources/wateruse. $\mathrm{htm}>$.

Meyer, M.H., B.K. Behe, and J. Heilig. 2001. The economic impact and perceived environmental effect of home lawns in Minnesota. HortTechnology 11:585-590.
Milesi, C., S.W. Running, C.D. Elvidge, J.B. Dietz, B.T. Tuttle, and R.R. Nemani. 2005. Mapping and modeling the biogeochemical cycling of turf grasses in the United States. Environ. Mgt. 36:426-438.

Mintenko, A.S., S.R. Smith, and D.J. Cattani. 2002. Turfgrass evaluation of native grasses for the northern Great Plains region. Crop Sci. 42: 2018-2024.

Mugaas, R. 1995. LILaC: Low-input lawn care. Minn. Ext. Serv. Metro Cluster, Univ. Minn.

Peters, E.B., R.V. Hiller, and J.P. McFadden. 2011. Seasonal contributions of vegetation types to suburban evapotranspiration. J. Geophys. Res. 116:G01003.

Qian, Y., R.F. Follett, and J.M. Kimble. 2010. Soil organic carbon input from urban turfgrasses. Soil Sci. Soc. Amer. J. 74:366-371.

Robbins, P. and T. Birkenholtz. 2003. Turfgrass revolution: Measuring the expansion of the American lawn. Land Use Policy 20:181-194.

Robbins, P., A. Polderman, and T. Birkenholtz. 2001. Lawns and toxins: An ecology of the city. Cities 18:369-380.

Robert, J.A. 1996. Green consumers in the 1990s: Profile and implications for advertising. J. Bus. Res. 36:217-231.

Samdahl, D.M. and R. Robertson. 1989. Social determinants of environmental concern. Environ. Behav. 21:57-81.

Smith, S., Jr. and R. Whalley. 2002. A model for expanded use of native grasses. Native Plants Journal. 3:38-49.

Spinti, J.E., R. Hilaire, and D. VanLeeuwen. 2004. Balancing landscape preferences and water conservation in a desert community. HortTechnology 14:72-77.

State of Minnesota. 2010. Minnesota Statute 18C.60: Phosphorous turf fertilizer use restrictions. Office of the Revisor of Statutes, St. Paul, MN. <https://www.revisor.mn.gov/statutes/?id= $18 \mathrm{C} .60 \&$ year $=2011>$.

State of Wisconsin. 2011. Wisconsin Statute 94C.643: Restrictions on the use and sale of fertilizer containing phosphorus. Legislative Reference Bureau, Madison, WI. <http://docs. legis.wi.gov/statutes/statutes/94/643>.

Turgeon, A.J. 2005. Turfgrass management. 7th Ed. Prentice-Hall, Englewood Cliffs, NJ.

Watkins, E., S. Fei, D. Gardner, J. Stier, S. Bughrara, D. Li, C. Bigelow, L. Schleicher, B. Horgan, and K. Diesburg. 2011. Low-input turfgrass species for the north-central United States. Appl. Turfgrass Sci. 1-11. doi:10.1094/ ATS-2011-0126-02-RS.

Wolfe, J. and J.M. Zajicek. 1998. Are ornamental grasses acceptable alternatives for lowmaintenance landscapes? J. Environ. Hort. 16: $8-11$.

Yabiku, S.T., D.G. Casagrande, and E. FarleyMetzger. 2008. Preferences for landscape choice in a southwestern desert city. Environ. Behav. 40:382-400.

Yue, C., J.H. Dennis, B.K. Behe, C.R. Hall, B.L. Campbell, and R.G. Lopez. 2011. Investigating consumer preference for organic, local, or sustainable plants. HortScience 46:610-615.

Yue, C. and C. Tong. 2009. Organic or local? Investigating consumer preference for fresh produce using a choice experiment with real economic incentives. HortScience 44:366-371.

Zadegan, Y.R., B.K. Behe, and R. Gough. 2008 Consumer preferences for native plants in montana residential landscapes and perceptions for naturalistic designs. J. Environ. Hort. 26:109-114.

Zheng, B., Y. Zhang, and J. Chen. 2011. Preference to home landscape: Wildness or neatness? Landsc. Urban Plan. 99:1-8. 